\title{
Refractory Pseudotumour Cerebri in a Pediatric Case
}

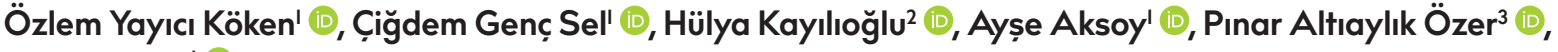 \\ Deniz Yüksel' (1)
}

'Department of Pediatric Neurology, Dr. Sami Ulus Children's Hospital, Ankara, Turkey

2Department of Pediatric Neurology, Muğla Sıtkı Koçman University School of Medicine, Muğla, Turkey

${ }^{3}$ Department of Ophtalmology, Ufuk University School of Medicine, Ankara, Turkey

ORCID IDs of the authors: Ö.Y.K. 0000-0003-2II2-8284; C.G.S. 0000-0002-3644-3I24; H.K. 0000-000I-7335-I985; A.A. 0000-000I-75331638; P.A.Ö. 0000-0002-6298-650I; D.Y. 0000-0002-6298-650I.

Cite this article as: Yayııı Köken Ö, Genç Sel Ç, Kayılıoğlu H, Aksoy A, Altıaylık Özer P, Yüksel P. Refractory Pseudotumour Cerebri in a Pediatric Case. Cyprus J Med Sci 2019; 4(2): I5I-3.

\begin{abstract}
Pseudotumour cerebri (PTC) is traditionally defined as increased intracranial pressure (ICP) $>200 \mathrm{mmH}_{2} \mathrm{O}$ with non-focal neurological findings, except the sixth-nerve palsy, and normal cerebrospinal fluid (CSF) composition without brain pathology or evidence of venous thrombosis. A 6-years-old girl was referred to our clinic for blurred vision in her left eye and a progressive headache. Her history was positive for a progressive vision loss in the left eye. Both optic disks were blurred and swollen. The opening pressure of CSF was $310 \mathrm{~mm} /$ $\mathrm{H}_{2} \mathrm{O}$. Despite the repeated lumbar punctures (LP) and medical treatment, the patient had to undergo the optic nerve sheath fenestration. A consequent shunt procedure had to be performed due to a persistently high CSF level. In this report, we emphasize that if surgical procedures can be applied earlier in refractory PTC cases, better results of visual improvement may be observed. In this report, we emphasize that early surgical treatment in refractory PTC cases results in better visual improvement.
\end{abstract}

Keywords: Pseudotumour cerebri, refractory, optic nerve sheet fenestration

\section{INTRODUCTION}

Pseudotumour cerebri (PTC), also known as idiopathic intracranial hypertension, is defined as the presence of papilledema with a normal neurologic examination, except for cranial nerve abnormalities, no structural brain lesions, and the absence of abnormal meningeal enhancement on neuroimaging, normal cerebrospinal fluid (CSF) composition, and intracranial pressure (ICP) $>280 \mathrm{~mm}$ in children, or $>250 \mathrm{~mm}$ in nonobese, nonsedated children (I). Since there are no universally accepted diagnostic criteria for PTC in children, the evaluation and management are usually determined on a case-by-case basis, family, and the clinician together. Most pediatric PTC cases are primary, whereas secondary causes can be listed as medications, such as antibiotics, chronic steroid use, growth hormone replacement, rethynoids, and thyroid replacement or diseases, such as hypervitaminosis A and E, hypovitaminosis D, Down syndrome, Addison disease, chronic kidney disease, and anemia $(2,3)$. Obesity is one of the most important etiologies of secondary PTC (4). The main goal of the treatment is to prevent the visual loss caused by the elevated CSF pressure. Poor visual acuity and severe optic disk edema at presentation are risk factors for visual loss (3). Medical and surgical methods are recommended for the treatment of PTC, but there is no universally accepted method. In this report, we aimed to present a refractory case of pediatric PTC resulting in permanent visual impairment despite oral medications and surgical procedures.

\section{CASE PRESENTATION}

Written informed consent was obtained from the patient's parents. A 6-years-old girl was admitted to our hospital with blurred vision in her left eye and a progressive headache that had started 10 days before. She was born from non-consanguineous parents with a normal prenatal, natal, and postnatal history. She was not obese or overweight, weighing $33 \mathrm{~kg}$, and with a body mass index of $22 \mathrm{~kg} / \mathrm{m}^{2}$. On an ophthalmological examination, both optic disks were blurred and swollen with a visual acuity of 20/200 on the left eye and 20/30 on the right eye. Aside from these findings, her neurological history and examination were completely normal. The blood count and biochemical tests were within the normal 
range, including C-reactive protein, the erythrocyte sedimentation rate, and vasculitis markers such as the rheumatoid factor, anti-nuclear antibody, cANCA, and pANCA. Cranial magnetic resonance imaging (MRI) revealed an empty sella due to invagination to the sella turcica of the suprasellar cistern and accumulation of fluid in the optic nerve sheath. The MRI venography was normal, which was performed to exclude cerebral venous sinus thrombosis. The lumbar puncture (LP) was planned with sedation, and the opening pressure of the CSF was measured at $310 \mathrm{mmH}_{2} \mathrm{O}$. A CSF analysis revealed no abnormalities. The patient was evaluated for primary and secondary causes of PTC using biochemical tests, CSF analysis, and neuroimaging. To rule out sarcoidosis, the level of CSF angiotensin-converting enzyme was measured, which was within a normal range. The patient was initially given $10 \mathrm{mg} / \mathrm{kg} /$ day of peroral acetolazolamide. Despite treatment with acetazolamide for 3 days, her complaints continued, the severity of headache increased, and visual acuity was deteriorated to hand motion on both eyes. The cerebrospinal fluid pressure was measured 3 days later, and the opening pressure of CSF under sedation with midazolam was $570 \mathrm{mmH}_{2} \mathrm{O}$, while it dropped to $150 \mathrm{mmH}_{2} \mathrm{O}$ as the closing pressure. The reason for this rapid decrease in the CSF pressure was that the increased flow rate of CSF could not be controlled. Pulse steroid treatment ( $30 \mathrm{mg} / \mathrm{kg} /$ day for 5 days) was initiated, while the search for a center that could perform the planned optic nerve fenestration procedure continued. At the end of the second day of pulse steroid treatment, ICP was measured as $440 \mathrm{mmH}_{2} \mathrm{O}$. Repeated ophthalmological examination revealed the left optic disk pallor. The connection with the surgery center was achieved on the I3th day of the follow-up. On the I5th day of her hospitalization, the optic nerve sheath fenestration (ONSF) was performed on her left eye. The visual acuity in the left eye did not show any improvement after the surgery, although the patient was free of headaches during her follow-up.

About a year later, she was re-admitted to hospital for severe headache and vomiting. The patient had no follow ups for about a year. During this time period, she was on topiramate and acetolazolamide but had quit her medications during the last week. Her right optic disk margins were blurred and swollen in the fundoscopic examination, whereas her left optic disk was totally pale, which was a sign of optic atrophy. Her visual acuity was 20/200 in the right eye and hand motions on left eye. Repeated cranial MRI and MRI venography revealed the same pathologies that were reported previously. The opening CSF pressure was measured as $610 \mathrm{mmH}_{2} \mathrm{O}$. A new treatment consisting of acetolazolamide $(10 \mathrm{mg} / \mathrm{kg} /$ day $)$ and topiramate $(3 \mathrm{mg} /$ $\mathrm{kg} / \mathrm{day}$ ) was initiated. The control CSF pressure after I week on medications was measured as $300 \mathrm{mmH}_{2} \mathrm{O}$. After 3 months, she presented with an increased loss of vision in her right eye. Her ophthalmological examination revealed an increase in the right optic disk edema. The opening pressure of the CSF was measured as $730 \mathrm{mmH}_{2} \mathrm{O}$. At that point, an urgent right ONSF was performed. After the second ONSF, the pressure of the CSF persisted at extremely high levels despite the oral medications, and the patient was referred to a neurosurgery clinic for a ventriculoperitoneal shunt (VPS) procedure.

\section{DISCUSSION}

Pseudotumour cerebri is traditionally defined as increased intracranial pressure (ICP) $>200 \mathrm{mmH}_{2} \mathrm{O}$ with non-focal neuro- logical findings, except the sixth-nerve palsy, and a normal CSF composition without brain pathology and no evidence of venous thrombosis (I-3).

The first case was reported in 1893 with an increased ICP of unknown etiology. The term of PTC was first used by Nonne. The term benign intracranial hypertension has been widely used to indicate a similar entity, but the visual morbidity of the pressure cannot be called benign, so this term is no longer used in the literature as expected. After 2013, the PTC syndrome was widely accepted as an umbrella term (5). Based on the etiology, PTC can be classified in three groups: primary, secondary, and atypical. Many causes of the secondary PTC have been reported, and PTC in children is often secondary $(2,5)$.

The main pathophysiologic mechanism is the impairment in the CSF flow dynamics. The CSF hypersecretion or impaired CSF resorption are mainly proposed as mechanisms of PTC. In the literature, several mechanisms due to vitamin A, obesity, hormones, natriuretic peptides, and aquaporin have been reported; however, the exact pathophysiological pathways remain obscure $(5,6)$

It has a broad clinical spectrum, ranging from asymptomatic papilledema to reduced consciousness and total loss of vision. Dramatic clinical presentations, such as bilateral abducens palsy in an infant with reduced consciousness and acute blindness, have been reported. The most common symptom is headache (7). Visual changes such as diplopia, transient visual obscurations, loss of visual acuity, or visual field have also been reported. Total visual loss is not common but is the most feared complication of the disease.

In this report, our patient presented with a severe headache and concurrent visual loss. Other presentations such as back pain, pulsatile or non-pulsatile, bilateral and fluctuating tinnitus, diplopia, nocturia, dizziness, photophobia, and radicular pain are also less commonly reported symptoms seen in patients with $\operatorname{PTC}(7,8)$.

MRI findings that suggest an elevated ICP in adults and children with PTC have been described and include flattening of the posterior sclera, distension of the perioptic subarachnoid space, enhancement of the prelaminar optic nerve, tortuosity of the orbital optic nerve, intraocular protrusion of the prelaminar optic nerve, and an empty sella (9). Our patient had an empty sella due to the invagination of the suprasellar cistern to the sella turcica and accumulation of fluid in the optic disk sheath.

The treatment goal of PTC is normalizing the CSF pressure to prevent loss of vision. Treatment modalities in children vary between different centers. The traditional treatment modality is repetitive LP and surgical shunting supported by medical therapy. Repetitive LP is not thought to be a suitable medical option in children with refractory PTC due to patient discomfort. Traditionally, acetolazolamide, which is a carbonic anhydrase inhibitor that reduces the CSF production, is the preferred initial medical treatment, which was also the first choice in our patient (I0). Steroid and topiramate therapy are other conventional treat- 
ment choices. Severe and medically refractory cases of PTC are generally treated surgically by using ONSF and VPS, which are known to be effective in reducing papilledema and improving or stabilizing visual function in almost all patients. The sequence of treatment modalities is not exactly clear in refractory PTC. Generally, less severe cases are treated medically. A Cochrane Collaboration review found no sufficient data to support the superiority of one type of surgery over the other (II). Shunting procedures have resulted in permanent surgical complications according to previous studies $(12,13)$. In our study, the ONSF of the left eye was performed immediately when the optic disk pallor was observed to improve vision loss. Clinical experiences support that the unilateral ONSF protects from vision loss in the other eye, too. In our case, opposite to this common belief, this expected protective effect of ONSF was not observed, although it was performed bilaterally in follow ups. Even after these interventions, the patient had to undergo a VPS operation. We believe that the optimal timing of surgical procedures such as ONSF or VPS in refractory cases should be discussed carefully during their follow ups and may be regarded as the first-line choice in these cases. Advanced refractory PTC algorithms are needed based on new clinical evidence from future studies.

Informed Consent: Written informed consent was obtained from the parents of the patients who participated in this study.

Peer-review: Externally peer-reviewed.

Author contributions: Concept - C..G.S., Ö.Y.K.; Design - C..G.S.; Supervision - A.A., D.Y.; Resource - Ö.Y.K., H.K.; Materials - C.G.S., Ö.Y.K., H.K.; Data Collection and/or Processing - C.G.S., Ö.Y.K., H.K., P.A.Ö.; Analysis and/or Interpretation - C.G.S., Ö.Y.K., H.K., P.A.Ö.; Literature Search - C.G.S., Ö.Y.K., H.K., A.A., D.Y.; Writing - C.G.S., Ö.Y.K., P.A.Ö.; Critical Reviews - C..G.S., Ö.Y.K., P.A.Ö., A.A., D.Y.

Acknowledgement: All authors thank all the patient and her family members for their participation in this study.

Conflict of Interest: The authors have no conflicts of interest to declare.
Financial Disclosure: The authors declared that this study has received no financial support.

\section{REFERENCES}

I. Friedman DI, Liu GT, Digre KB. Revised diagnostic criteria for the pseudotumor cerebri syndrome in adults and children. Neurology 2013; 81: II59-65. [CrossRef]

2. Rangwala LM, Liu GT. Pediatric idiopathic intracranial hypertension. Surv Ophthalmol 2007; 52:597-617. 2. Phillips PH. Pediatric pseudotumor cerebri. Int Ophthalmol Clin 2012; 52: 51-9. [CrossRef]

3. Rook BS Phillips PH. Pediatric pseudotumor cerebri Curr Opin Ophthalmol 2016; 27: 416-9. [CrossRef]

4. Paley GL, Sheldon CA, Burrows EK, Chilutti MR, Liu GT, McCormack SE. Overweight and obesity in pediatric secondary pseudotumor cerebri. Am J Ophthalmol 2015; 159: 344-52. [CrossRef]

5. Burkett JG, Ailani J. An Up to Date Review of Pseudotumor Cerebri Syndrome. Curr Neurol Neurosci Rep 2018; 18: 33. [CrossRef]

6. Portelli $M$, Papageorgiou P. An update on idiopathic intracranial hypertension. Acta Neurochir 2016; 159: 49I-9. [CrossRef]

7. Wall M, Kupersmith MJ, Kieburtz KD, Corbett JJ, Feldon SE, Friedman $\mathrm{DI}$, et al. The idiopathic intracranial hypertension treatment trial. JAMA Neurolgy 2014; 71: 693-70I. [CrossRef]

8. Thambisetty M, Lavin P, Newman N, Biousse V. Fulminant idiopathic intracranial hypertension. Neurology 2007; 68: 229-32. [CrossRef]

9. Brodsky $M C$, Vaphiades $M$. Magnetic resonance imaging in pseudotumor cerebri. Ophthalmology 1998; 105: 1686-93. [CrossRef]

10. Thurtell M, Wall M. Idiopathic intracranial hypertension (pseudotumor cerebri): recognition, treatment, and ongoing management. Curr Treat Options Neurol 2012; 15: 1-12. [CrossRef]

II. Fonseca PL, Rigamonti D, Miller NR, Subramanian PS. Visual outcomes of surgical intervention for pseudotumour cerebri: optic nerve sheath fenestration versus cerebrospinal fluid diversion. $\mathrm{Br} \mathrm{J}$ Ophthalmol 2014; 98: 1360-3. [CrossRef]

12. Fonseca PL, Rigamonti D, Miller NR, Subramanian PS. Visual outcomes of surgical intervention for pseudotumour cerebri: optic nerve sheath fenestration versus cerebrospinal fluid diversion. $\mathrm{Br} \mathrm{J}$ Ophthalmol 2014; 98: 1360-3. [CrossRef]

13. deSouza R, Toma A, Watkins L. Medication overuse headache-an under-diagnosed problem in shunted idiopathic intracranial hypertension patients. Br J Neurosurg 2014; 29: 30-4. [CrossRef] 